\title{
Thermal Analysis of High Density Permanent Magnet Synchronous Motor Based on Multi Physical Domain Coupling Simulation
}

\author{
ShiJun Chen****, Qi Zhang ${ }^{\dagger}$, Biao He*, SuRong Huang* and Dou-Dou Hui*
}

\begin{abstract}
In order to meet the thermal performance analysis accuracy requirements of high density permanent magnet synchronous motor (PMSM), a method of multi physical domain coupling thermal analysis based on control circuit, electromagnetic and thermal is presented. The circuit, electromagnetic, fluid, temperature and other physical domain are integrated and the temperature rise calculation method that considers the harmonic loss on the frequency conversion control as well as the loss non-uniformly distributed and directly mapped to the temperature field is closer to the actual situation. The key is to obtain the motor parameters, the realization of the vector control circuit and the accurate calculation and mapping of the loss. Taking a 48 slots 8 poles high density PMSM as an example, the temperature rise distribution of the key components is simulated, and the experimental platform is built. The temperature of the key components of the prototype machine is tested, which is in agreement with the simulation results. The validity and accuracy of the multi physical domain coupling thermal analysis method are verified.
\end{abstract}

Key words: Coupling simulation, Multi physical domain, Permanent magnet synchronous motor, Thermal calculation

\section{Introduction}

The high density, light weight, high reliability, low speed and high output, and constant power wide speed regulation are pursued by high density PMSM. The motor power density is improved by increasing the electromagnetic load as far as possible in the limited space, leading to the limited size of the high density PMSM, higher electromagnetic load and heat load than common motor. These features are very strict requirements for the correct evaluation of the thermal performance of the motor [1-3]. The life and operating reliability of motor are decided by the thermal performance of the motor, especially the temperature rise of stator winding and the rotor magnet. Sharp rise of motor temperature will lead to winding insulation failure, substantial deterioration of the permanent magnet performance, or even complete loss of driving capability. As long as the local high temperature breakdown occurs in the motor, the motor will be forced to a stop and be repaired. Therefore, when motor is designed and manufactured, not only the potentials of the motor body and the improvement of the power density but also the generation of local hot spots must be taken into full consideration. Those can ensure the safe and reliable

$\dagger$ Corresponding Author: School of Mechatronic Engineering and Automation, Shanghai University, Shanghai, China.

(qizhang@staff.shu.edu.cn)

* School of Mechatronic Engineering and Automation, Shanghai University, Shanghai, China. (ch_sh_jun@sina.cn)

** School of Physics and Electronic Engineering, Anqing Normal University, Anqing, China. (ch_sh_jun@sina.cn)

Received: January 28, 2016; Accepted: May 25, 2016 operation of the electric drive system. Thus, accurate analysis of the motor's temperature distribution becomes an extremely important procedure in the design of the motor. It is also the key to realizing the high power density and reliability of the vehicle motor.

Accurate calculation of the loss and distribution is the premise of accurate simulation of the thermal performance on the motor. The loss caused by the motor control circuit is not negligible, especially for the accurate calculation of the motor temperature rise. There is a fair amount of domestic and foreign research literature on this aspect. In [4], an analysis of the harmonic loss of a 150KW PMSM based on SVPWM control mode was carried out. In $[5,6]$, the iron loss distribution of PMSM under PWM control was studied. In [7], a permanent magnet motor was taken as an example with the principle of vector control and finite element analysis, a two dimensional model of permanent magnet motor was established and the regional loss of the motor under different conditions was analyzed in detail. In [8], the calculation method of temperature rise of the motor under variable frequency control was presented, the experimental results showed that the temperature rise of the motor can be calculated accurately. In [9], the calculation method of the eddy current loss in the permanent magnet under PWM modulation was introduced. In [10], the iron loss characteristics of induction motor under PWM were studied, and a new type of iron loss equivalent resistance model was proposed, which considered the operating conditions and the PWM wave characteristics. It can be seen that, considering the actual motor work in inverter supply with high harmonics, 
it would produce additional permanent magnet eddy current loss and harmonic iron loss, influencing the calculation of temperature rise significantly.

Computer simulation technology is critical for the accurate calculation of temperature rise of the motor, there are a lot of literatures in this field, mainly about thermal network model simulation and finite element model simulation calculation method. The average temperature of the motor components is calculated by the thermal network method, which has the advantages of fast calculation, clear heat transfer path that facilitates program evaluation and thermal management. In [11, 12], thermal network simulation method was used. But the simulation precision of the thermal network method was difficult to guarantee. In $[13,15]$, the finite element model simulation method was used, which can accurately calculate the motor temperature rise and distribution. Currently, with finite element software, the calculation of temperature rise is mainly carried out through: temperature field calculation method, the thermoelectric two-way coupling calculation method and fluid-solid coupling calculation method. Temperature field calculation method had the characteristics that the heat production rate would be evenly distributed on the heating element [13], which failed to reflect the distribution of the actual loss, and also needed to set the heat transfer coefficient affected by temperature. Thermoelectric two-way coupling method [14] can reflect the distribution of motor loss but unable to accurately determine boundary coefficient of heat transfer. Fluid-solid coupling calculation method [15] did not need to apply the boundary conditions, avoiding the determination of fluid-solid boundary heat transfer coefficient, but the phenomenon of non-uniform loss distribution was not taken into account. Therefore, researching and developing a kind of simulation calculation method that couples electromagnetic field, temperature field and the fluid field is very important to correctly capture the maximal hot spot inside motor. But the research on this topic is rarely seen, especially combined with control circuit of coupling simulation technology.

Considering circuit, electromagnetic, fluid, temperature, and other physical domain, a method of multi physical domain coupling thermal analysis based on control circuit, electromagnetic and thermal is presented in this paper. The temperature rise calculation method that considers the harmonic loss on the frequency conversion control as well as the loss non-uniformly distributed and directly mapped to the temperature field is closer to the actual situation, finally the verification experiment is carried on prototype machine.

\section{Main Process and Key Technology of Multi Physical Domain Coupling Thermal Analysis}

The general idea of realizing multi physical domain coupling analysis is to import the current from motor control circuit into the electromagnetic calculation, then directly map heat loss calculated by the electromagnetic to temperature field for the analysis and calculation, getting the temperature of key components in the motor, realizing mutual coupling of control circuit, electromagnetic calculation and thermal analysis.

\subsection{Main process of coupling simulation calculation}

As shown in Fig. 1, the main process of the circuit, electromagnetic, thermal coupling simulation are: 1) The motor model is built by inputting the dimensional parameters. Assuming the working temperature of the permanent magnet, stator and rotor core, winding are $T_{p m 0}$,

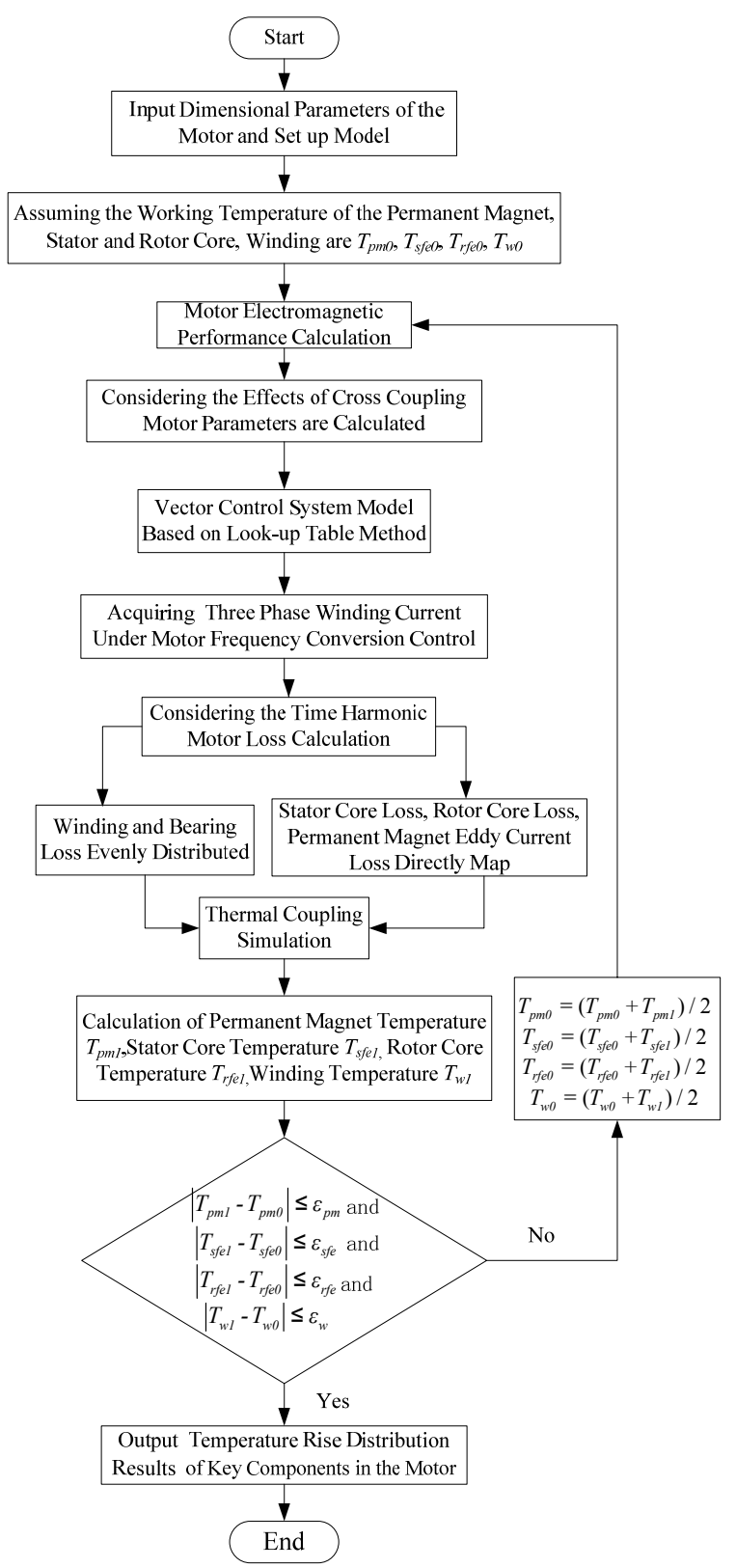

Fig. 1. Multi physical domain coupling simulation calculation process 
$T_{s f e 0}, T_{r f e 0}, T_{w 0}$. The electromagnetic performances of the motor are calculated and the parameters such as the inductance by considering the cross coupling, resistance and flux linkage are obtained. 2) Establish a model of vector control system based on parameter look-up table method which is based on resistance and inductance and other parameters of the motor. The look-up table is made of $I_{d}$ and $I_{q}$ corresponding to motor speed and torque. Then the three-phase winding current is obtained and imported into the electromagnetic calculation for motor loss calculation. The loss are divided into two parts: one part is winding copper loss and the bearing friction loss, which is uniformly distributed to the temperature field, while another part of the loss, that is stator iron core loss and permanent magnet eddy current loss, is directly mapped to the temperature field. 3) The motor temperature rise distribution of the key components is obtained by the thermal coupling simulation calculation, including water channel entrance, stator and rotor core, stator winding, and permanent magnet. 4) The calculation of the key components' temperature rise and the assumed operating temperature are compared with each other, if the same, output the key components' temperature rise distribution results and end calculation process. Otherwise, according to $T_{p m 0}=\left(T_{p m 0}+T_{p m 1}\right) / 2, T_{s f e 0}=\left(T_{s f e 0}+T_{s f e l}\right) / 2, T_{r f e 0}=$ $\left(T_{r f e 0}+T_{r f e l}\right) / 2, \quad T_{w 0}=\left(T_{w 0}+T_{w l}\right) / 2$, reset the working temperature until the simulation and assumed temperature meeting errors requirement of $\varepsilon_{p m}, \varepsilon_{s f e}, \varepsilon_{r f e}, \varepsilon_{w}$.

\subsection{Key technology of coupling simulation}

\subsubsection{Inductance parameters calculation}

In order to achieve accurate vector control of permanent magnet synchronous motor, the Maxwell software are used for calculating inductance, resistance, flux linkage and other parameters, which are useful for building accurate mathematical motor model. When calculating the inductance parameters, the cross coupling effect of $\mathrm{d}-\mathrm{q}$ axis current is considered, but the influence of leakage inductance is neglected, the main steps for calculating inductance parameters are: Firstly, the stator current vector $i_{s}$, the noload flux linkage vector $\psi_{\text {mag }}$ and the load flux linkage vector $\psi_{\delta}$ are determined according to the Maxwell software. Then according to the vector relation of $i_{s}, \psi_{\text {mag }}$ and $\psi_{\delta}$ on the $\mathrm{d}$-q coordinates, the formula for calculating the inductance of $\mathrm{d}-\mathrm{q}$ axis can be derived:

$$
\begin{gathered}
L_{\mathrm{d}}\left(i_{d}, i_{q}\right)=\frac{\psi_{\mathrm{mag}}-\psi_{\delta}\left(i_{d}, i_{q}\right) \cos \theta}{i_{d}} \\
L_{\mathrm{q}}\left(i_{d}, i_{q}\right)=\frac{\psi_{\delta}\left(i_{d}, i_{q}\right) \sin \theta}{i_{q}}
\end{gathered}
$$

where $\psi_{\text {mag }}$ is the no-load flux linkage vector, $\psi_{\delta}$ is the load flux linkage vector, $i_{s}$ is current space vector, $\theta$ is the

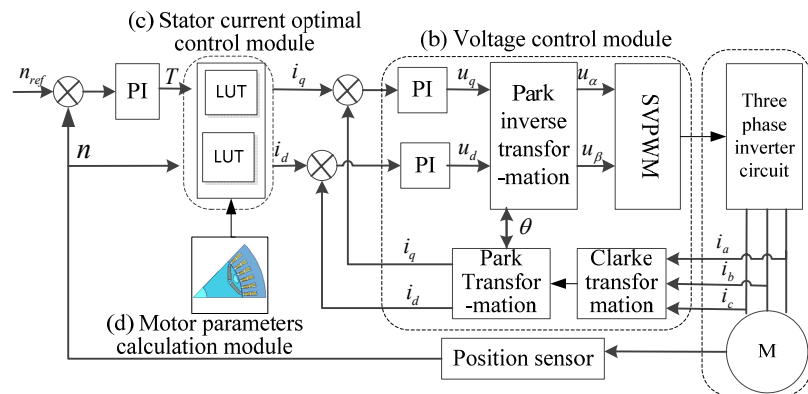

(a) Main circuit

Fig. 2. Vector control system

included angle between $\mathrm{d}$ axis and $\psi_{\delta}, \varphi$ is the included angle between $\mathrm{q}$ axis and $i_{s}, L_{d}$ is the armature reaction inductance of d axis, $L_{q}$ is the armature reaction inductance of q axis, $i_{d}$ and $i_{q}$ are current vectors of d-q axis.

\subsubsection{Vector control circuit}

In motor design, taking into account the actual operating condition of motor, maximum torque/current ratio control mode is used when the motor is running below base speed, weak magnetic control mode is used when motor is running above the base speed. The vector control block diagram is shown in Fig. 2, mainly including the main circuit, voltage control module, stator current optimal control module and motor parameters calculation module. Comparison between the given speed $n_{\text {ref }}$ and actual speed $n$, the $L d, L q$ and other parameters are calculated by motor parameters calculation module. The current $i_{d}$ and $i_{q}$ are given to voltage control module through stator current optimal control module based on look-up table method to realize SVPWM modulation mode, controlling the main circuit and operation of motor.

\subsubsection{Loss calculation of multi physical domain coupling simulation}

Accurate calculation of the motor loss is the premise for calculating the temperature rise of the motor. At the same time, the motor loss is directly mapped to the temperature field rather than the uniform distribution, which is closer to the actual temperature rise. In this paper, not only the effect of different frequency on the iron loss is considered, but also the influence of temperature on the eddy current loss of the permanent magnet is considered. The B-P curve changing with the frequency of the core material is set in the Maxwell software. Neglect the effect of temperature on the iron loss, set the B-H curve at reference temperature and the linear relationship of the $\mathrm{B}-\mathrm{H}$ curve at reference temperature and other temperature for the permanent magnet material. The stator and rotor core loss and eddy current loss of permanent magnet are calculated, then directly mapped to the Fluent on the ANSYS-Workbench to achieve the calculation of the motor temperature rise.

In order to accurately calculate the copper loss of AC 
windings, the current skin effect is considered, ANSYS Maxwell Eddy-current is used to obtain the conductor current density change curve at the rated current of the three-phase windings. The copper loss of the AC winding is calculated according to the formula (3)[16].

$$
P_{c u}=\rho_{c u} l_{w} \sum_{i=1}^{m}\left(J_{R i}^{2}+J_{X i}^{2}\right) \Delta_{i}
$$

where $J_{R i}$ and $J_{X i}$ are respectively for the $i$ unit real and imaginary part of the current density, $\Delta_{i}$ is the area of the $i$ unit, $m$ is the unit number of A phase winding, $\rho_{c u}$ and $l_{w}$ are respectively for the resistivity and the winding half turn length of copper wire.

Consider the bearing friction loss, and neglect the windage and friction loss. In the case of deep groove ball bearing, friction torque of rolling bearing is mainly composed of two parts, the friction torque $T_{1}$ and the viscous friction torque $T_{v}$ caused by the external load. It can be calculated by empirical formula (4), (5) [17]:

$$
\begin{gathered}
T_{1}=f_{1} F_{\beta} d_{m} \\
T_{v}=\left\{\begin{array}{r}
160 f_{0} d_{m}^{3} \cdot 10^{-7} \quad v_{0} n<2000 \\
\left(v_{0} n\right)^{2 / 3} f_{0} d_{m}^{3} \cdot 10^{-7} \quad 2000 \leq v_{0} n
\end{array}\right.
\end{gathered}
$$

where $F_{\beta}$ is the calculation load of bearing $(\mathrm{N}), f_{1}$ is the coefficient related to bearing structure and load. For deep groove ball bearing, $f_{1}=0.0004\left(F_{S} / C_{S}\right)^{0.55}$, where $F_{S}$ is the equivalent static load for bearing $(\mathrm{N}) \cdot C_{S}$ is the basic rated static load of bearing $(\mathrm{N}) \cdot v_{0}$ is the kinematic viscosity of lubricant at operating temperature, $n$ is $\operatorname{speed}(\mathrm{r} / \mathrm{min}), f_{0}$ is a factor related to the type of bearing and the lubrication scheme, that can be found in literature [17]. Assuming that all friction loss is converted into heat, the calculation formula of bearing friction loss $P$ is as follow:

$$
P=\Omega\left(T_{1}+T_{v}\right)
$$

where $P$ is the bearing friction loss, $\Omega$ is the mechanical angular velocity, $T_{l}$ is the friction torque, $T_{v}$ is the viscous friction torque.

\section{Thermal Conductivity of PMSM Thermal Model}

The thermal conductivity is a key factor for calculating the temperature rise of the motor. It is necessary to make reasonable thermal conductivity equivalent for material to each component of the motor.

\subsection{Equivalent thermal conductivity calculation of stator slot}

The effective equivalent method should be adopted, to make the equivalent thermal conductivity truly reflect the thermal conductivity of the stator slot and meet the requirements of the finite element mesh. According to the equivalent method of stator slot presented by [18], the equivalent thermal conductivity is calculated, including two cases of no internal heat source equivalent calculation and internal heat source equivalent calculation.

Equivalent thermal conductivity calculation of no internal heat source:

$$
\lambda_{e}=\ln \frac{R_{n}}{R_{0}} /\left(\sum_{i=1}^{n} \frac{1}{\lambda_{i}} \ln \frac{R_{i}}{R_{i-1}}\right)
$$

Equivalent thermal conductivity calculation of internal heat source:

$$
\lambda_{s e}=\frac{1}{\frac{1}{\lambda_{0}}+2 \sum_{i=1}^{n} \frac{1}{\lambda_{i}} \ln \frac{R_{i}}{R_{i-1}}}
$$

where $\lambda_{e}$ is the thermal conductivity of no internal heat source, $\lambda_{s e}$ is the thermal conductivity of internal heat source, $R_{0}$ and $\lambda_{0}$ is the radius and thermal conductivity of inner circle, $R_{n}$ is the radius of outer circle. $R_{i}$ and $\lambda_{i}$ is the radius and thermal conductivity of $i$ layer inner wall. Therefore, the thermal conductivity of the insulating paper, the slot wall gap and the equivalent winding are calculated from (7) and (8).

\subsection{Equivalent thermal conductivity calculation of bearing}

According to the analysis method proposed for deep groove ball bearing in [19], the bearing equivalent model is divided into four regions. The first and second regions are bearing inner and outer rings, and the thermal conductivity is the actual material parameters. The formula (9) and (10) are used to calculate the equivalent thermal conductivity for third and fourth regions :

$$
\begin{gathered}
\lambda_{\text {eqr } 3}=\frac{\ln \left(r_{o i} / r_{i o}\right)}{2 \pi \cdot l_{T} \cdot R_{T a-a n n 1}} \\
\lambda_{\text {eqr } 4}=\ln \left(\frac{d_{o}}{d_{i}}\right) /\left(\frac{R_{\lambda-\text { ball }} \cdot R_{D e-g a p}}{R_{\lambda-\text { ball }}+R_{\text {De-gap }}} \cdot 2 \pi l\right)
\end{gathered}
$$

where $\lambda_{\text {eqr } 3}$ and $\lambda_{\text {eqr } 4}$ is the thermal conductivity of lubricating medium and multi material equivalent region, $r_{o i}$ and $r_{i o}$ is the inner radius and outer radius of the outer circle and inner circle, $l_{T}$ is axial length of the annular gap, $l$ is axial length of bearing region, $R_{\text {Ta-ann }}$ is the convection resistance of annulus in Taylor-Couette flow, $R_{\lambda \text {-ball }}$ is conduction resistance of spherical ball, $R_{\text {De-gap }}$ is the convection resistance of Dean flow in roll gap, $d_{o}$ and $d_{i}$ are the diameter of the inner raceway and outer raceway. 


\subsection{Equivalent thermal conductivity calculation of air gap between the stator and rotor}

In order to effectively simulate the thermal conduction of stator and rotor air gap, the effective thermal conductivity $\lambda_{\text {air }}$ is introduced [20], which has a great relationship with the rotating speed of air flow and the air dynamic viscosity. The thermal conductivity in the air gap between the stator and rotor can be calculated by the following formula [21].

$$
\begin{gathered}
\lambda_{\text {air }}=0.0019 \eta^{-2.9084} \mathrm{Re}^{0.4614 \ln (3.33361 \eta)} \\
\eta=R_{o} / R_{i} \\
\operatorname{Re}=\omega \delta / v
\end{gathered}
$$

where $\lambda_{\text {air }}$ is the equivalent thermal conductivity coefficient, $R_{o}$ is outer diameter of rotor, $R_{i}$ is inner diameter of stator, $\omega$ is linear velocity of rotor, $\delta$ is the length of air gap, $v$ is kinematic viscosity of air. Therefore, the equivalent thermal conductivity of stator and rotor air gap is calculated, according to the formula (11), (12), (13).

\section{PMSM Multiple Physical Domain Coupling Simulation Examples}

PMSM is a complicated structure model, in order to simplify the calculation process and get good calculation accuracy, thus, make the following assumptions:

1) The heat generated by heat source are mainly taken away by cooling water, ignore the heat exchange between outside surface of water jacket and surrounding air. And neglect the thermal radiant of every component of motor.

2) The motor winding copper loss, the bearing friction loss are distributed evenly in the winding and bearing.

3) The flow to cooling channel is perpendicular to the frame of cooling water inlet direction.

\subsection{Prototype machine main structure parameters and performance requirements}

In this paper, a 48 slot 8 pole high density PMSM is simulated and analyzed. The main performance requirements and dimensions are shown in Table 1. The water outside of the frame for cooling the motor is used, the prototype machine structure is shown in Fig. 3.
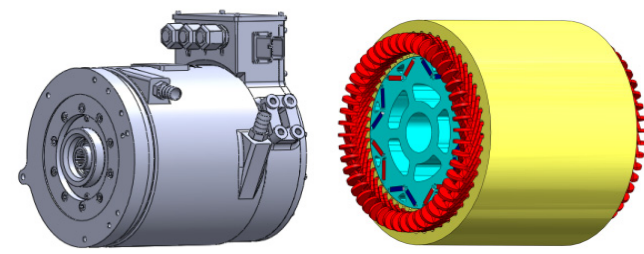

Fig. 3. Structure diagram of prototype machine
Table 1. Performance requirements and main dimensions of prototype machine

\begin{tabular}{c|c}
\hline Rated power & $42 \mathrm{~kW}$ \\
\hline Rated speed & $4000 \mathrm{r} / \mathrm{min}$ \\
\hline Rated torque & $100 \mathrm{~N} \cdot \mathrm{m}$ \\
\hline Maximum power & $88 \mathrm{KW}$ \\
\hline Maximum speed & $11500 \mathrm{r} / \mathrm{min}$ \\
\hline Maximum torque & $210 \mathrm{~N} \cdot \mathrm{m}$ \\
\hline DC bus voltage & $350 \mathrm{~V}$ \\
\hline Maximum current (RMS) & $360 \mathrm{~A}$ \\
\hline Core length & $160 \mathrm{~mm}$ \\
\hline Outer diameter of the stator & $230 \mathrm{~mm}$ \\
\hline Inner diameter of the stator & $43 \mathrm{~mm}$ \\
\hline Pole/slot & $8 / 48$ \\
\hline Ambient temperature & $25^{\circ} \mathrm{C}$ \\
\hline Cooling method & Water cooling \\
\hline
\end{tabular}

\subsection{Simulation results analysis}

In this paper, the simulation analysis and experimental tests of the prototype motor are included in two cases: the first operating condition is the speed of $4000 \mathrm{r} / \mathrm{min}$, the load 100 N.m. At this case, maximum torque current ratio control method is used in the constant torque region, and motor operates at this state for a long time. The second operating condition is the speed of $7000 \mathrm{r} / \mathrm{min}$, load $57 \mathrm{~N} . \mathrm{m}$ At this case, weak magnetic control method is used in the constant power region. The calculation method of temperature rise under other conditions is the same. Similarly, temperature rise calculation method mentioned in this paper can also be applied to other motors.

According to the inductance calculation method in the section 2.2.1, get the inductance parameters $L_{d}, L_{q}$ with change curve of the current $I_{d}, I_{q}$, as shown in Fig. 4.

According to the vector control circuit in section 2.2.2, maximum torque/current ratio control and weak magnetic
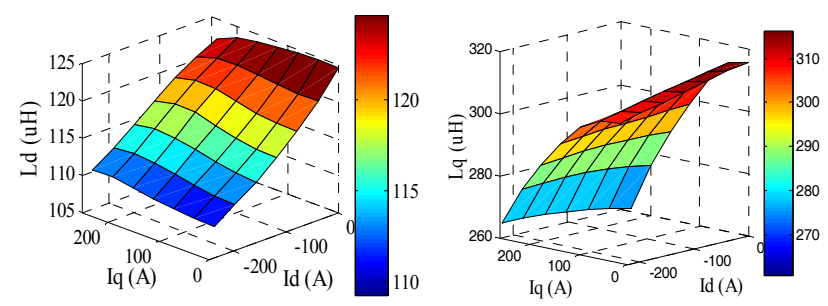

Fig. 4. Change curves of $L_{d}, L_{q}$ with $I_{d}, I_{q}$
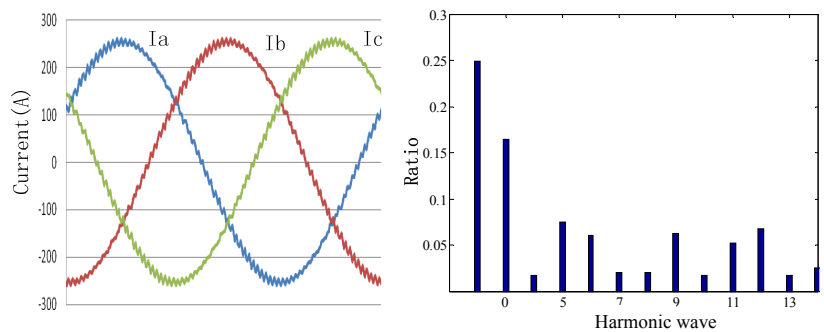

(a) Three-phase current waveform

(b) FFT

Fig. 5. Three phase current waveform under vector control 
control system simulation model of Matlab/Simulink is built, and the base speed is $4000 \mathrm{r} / \mathrm{min}$, the switching frequency is $10 \mathrm{KHz}$. The three-phase current waveform is obtained under the first operating condition of vector control, which is shown in Fig. 5(a). And for one phase of them, FFT decomposition is shown in Fig. 5(b). Under the condition of frequency conversion power supply, there are many high harmonics of three-phase current. The harmonic distortion rate is $2.32 \%$ and the frequency of the harmonic wave is around the frequency of the switch tube.

According to the method of calculating loss in section 2.2.3, use formula (3) for calculating winding copper loss that considers skin effect in the two operating conditions, respectively $508.2 \mathrm{~W}$ and $554.2 \mathrm{~W}$. The friction loss of the bearing under the two operating conditions is respectively $86.1 \mathrm{~W}$ and $218.5 \mathrm{~W}$ by formula (6). The loss of stator and rotor core, permanent magnet eddy current loss are calculated by Maxwell software under the two operating conditions, respectively $631.3 \mathrm{~W}, 7.1 \mathrm{~W}$ and $1195.7 \mathrm{~W}$, $13.5 \mathrm{~W}$.

The inlet water temperature is set for $48{ }^{\circ} \mathrm{C}$ with the water flow rate $12 \mathrm{~L} / \mathrm{min}$, the loss of the stator and rotor core is mapped directly to the Fluent temperature field with winding copper loss and bearing loss distributed evenly to the Fluent temperature field. Simulate and calculate the temperature rise of the motor under two operating

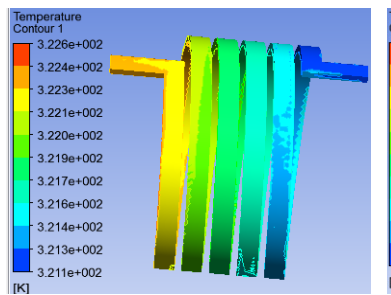

(a) Water jacket

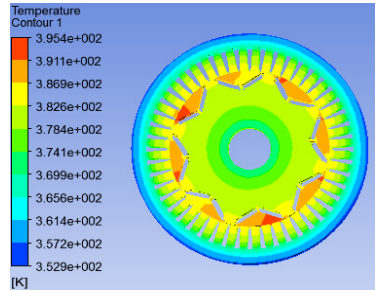

(c) Stator and rotor core

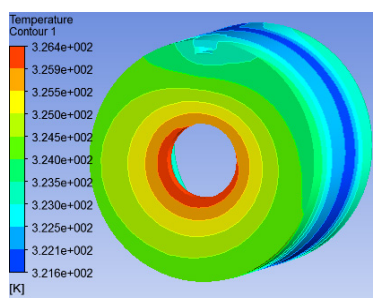

(e) Housing

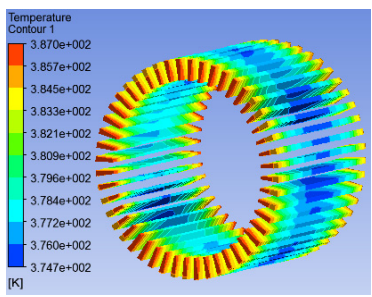

(b) Stator winding

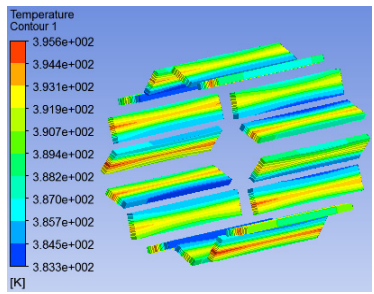

(d) Magnet

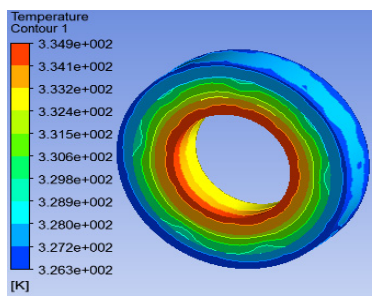

(f) Bearing
Fig. 6. Temperature distribution after considering the harmonic loss and loss direct mapping conditions, the simulation results are shown in Fig. 6, which shows the simulation results in the first case, the simulation method and results under second operating conditions are similar to the first case. Fig. 7 shows the simulation results calculated in the first operating condition, without considering the control circuit, while stator and rotor core loss and permanent magnet eddy current loss are evenly distributed to the temperature field.

The comparison between Fig. 6 and Fig. 7 shows that the temperature rise of each component without considering the harmonic loss is slightly lower. In the case of the loss that is directly mapped to the temperature field, the eddy current density of the permanent magnet is distributed on the surface and the maximum temperature is distributed on the surface of the permanent magnet, while in the case of even loss distribution, the maximum temperature of permanent magnet is distributed on the inner side, which is similar to the temperature rise distribution of the stator and rotor core.

Considering harmonic loss, the maximum temperature rise simulation results of the key parts of the motor are directly mapped to the temperature field under two operating conditions, which are shown in Table 2. The temperature of second case is higher than the first case, especially in permanent magnet and rotor core, the reason is that core loss and permanent magnet eddy current loss

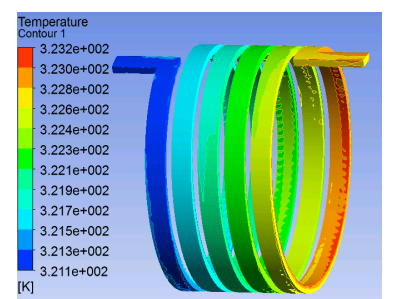

(a) Water jacket

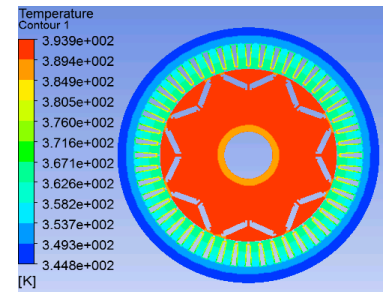

(c) Stator and rotor core

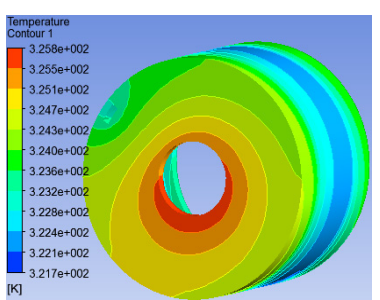

(e) Housing

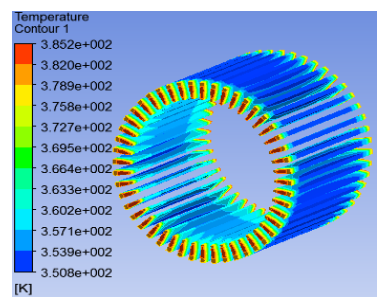

(b) Stator winding

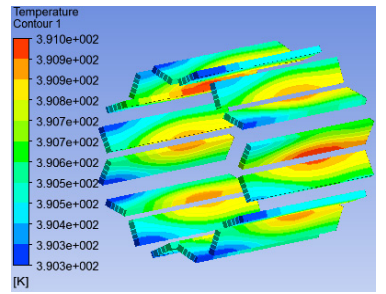

(d) Magnet

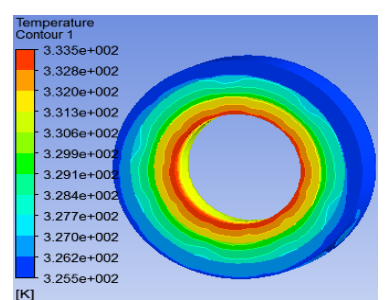

(f) Bearing
Fig. 7. Temperature distribution before considering the harmonic loss and loss direct mapping 
Table 2. Maximum temperature in main components of the prototype machine

\begin{tabular}{l|c|c}
\hline Operating condition & Components & Temperature $\left({ }^{0} \mathrm{C}\right)$ \\
\hline \multirow{4}{*}{$4000 \mathrm{r} / \mathrm{min}, 100 \mathrm{~N} \cdot \mathrm{m}$} & Water inlet & 48.0 \\
\cline { 2 - 3 } & Water outlet & 49.5 \\
\cline { 2 - 3 } & Winding & 113.8 \\
\cline { 2 - 3 } & Stator core & 114.8 \\
\cline { 2 - 3 } & Rotor core & 122.2 \\
\cline { 2 - 3 } & Magnet & 122.4 \\
\hline \multirow{4}{*}{$7000 \mathrm{r} / \mathrm{min}, 57 \mathrm{~N} \cdot \mathrm{m}$} & Water inlet & 48.0 \\
\cline { 2 - 3 } & Water outlet & 50.0 \\
\cline { 2 - 3 } & Winding & 119.2 \\
\cline { 2 - 3 } & Stator core & 120.0 \\
\cline { 2 - 3 } & Rotor core & 134.6 \\
\cline { 2 - 3 } & Magnet & 135.1 \\
\hline
\end{tabular}

Table 3. Comparison between simulation and experimental values in main components of the prototype machine

\begin{tabular}{c|c|c|c}
\hline $\begin{array}{c}\text { Operating } \\
\text { condition }\end{array}$ & Components & $\begin{array}{c}\text { Simulation } \\
\text { values }\left({ }^{\circ} \mathrm{C}\right)\end{array}$ & $\begin{array}{c}\text { Experimental } \\
\text { values }\left({ }^{\circ} \mathrm{C}\right)\end{array}$ \\
\hline $\begin{array}{c}4000 \mathrm{r} / \mathrm{min}, \\
100 \mathrm{~N} \cdot \mathrm{m}\end{array}$ & Winding & 113.8 & 112 \\
\cline { 2 - 4 } & Magnet & 122.4 & 123 \\
\hline $7000 \mathrm{r} / \mathrm{min}$, & Winding & 119.2 & 118 \\
\cline { 2 - 4 } $57 \mathrm{~N} \cdot \mathrm{m}$ & Magnet & 135.1 & 136 \\
\hline
\end{tabular}

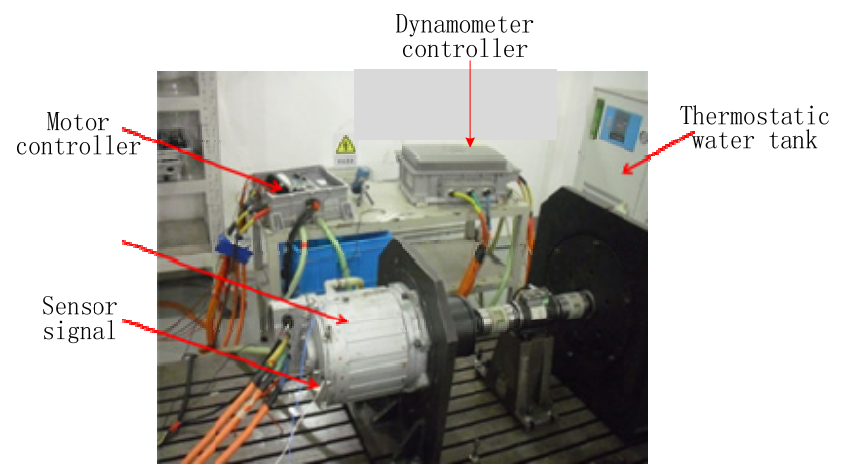

Fig. 8. Test platform for prototype machine

increase larger along with the increase of the speed. The maximum temperature of stator and rotor core, stator windings and permanent magnets are not exceeded. The temperature rise of the motor is closer to the actual situation, the calculation method is more effective.

\section{Experimental Verification}

The experiment platform has been set up, as shown in Fig. 8, in which two identical motors with the rated power $42 \mathrm{~kW}$ are driven with each other. The tested motor adopts torque control while the other motor uses speed control. In addition, the cooling system is used in this experiment. With the purpose of monitoring temperature variation in each component, thermal resistors are respectively placed at the end winding of motor, the outer wall of frame, the underside of rotor permanent magnet, the water inlet and the outlet of frame.

The comparison between the experimental results and the simulation values of the stator winding and rotor magnet is shown in Table 3, which shows that the temperature simulation values of the motor is close to the experimental value. The correctness of multi physical domain coupling simulation calculation method is demonstrated in this paper.

\section{Conclusions}

With consideration of interaction among multi physical domain, such as circuit, electromagnetic, temperature, fluid and other physical domain, this paper presents a multi physical domain coupling simulation calculation technology including control circuit, electromagnetic calculation and thermal analysis. The specific contributions in this paper are summarized as follows:

1) Compared with the traditional methods, both of heat in harmonic loss and non-uniformly distributed heat source are considered in multi physical domain coupling simulation calculation technology, through which heat source will be directly mapped into the temperature field to calculate the results. Thus, this proposed method will describe the distribution of temperature rise in the motor much more accurately.

2) There are three important technologies in multi physical domain coupling simulation calculation technology, which are the computation of inductance parameters, the vector control circuit and accurate loss calculation. In the computation of inductance parameters, consider the current cross coupling effect, which makes the inductance parameter calculation more accurate than that in traditional methods. Moreover, in order to design the model of motors more accurately, the vector control circuit uses the look-up table method. For the computation of loss, many more factors are considered, such as the friction loss in bearing, copper loss in skin effect and the harmonic loss.

3) In this paper, we take a machine for instance with the proposed method, whose basic properties are 48 slots, 8 poles and rated power $42 \mathrm{~kW}$. Simulation results are demonstrated that the coupling simulation computation is effective and accurate, also the results in analysis are in agreement with those in experiment. Thus, coupling simulation related to multi physical domain is an advanced technology and applicable for the temperature rise calculation of motors with fine prospect. 


\section{Acknowledgements}

This work was supported by the Shang Hai IndustryUniversity-Institute Cooperation Annual Plan Project under Grant No. Hu CXY-2015-014 . The General Project of Natural Science Research of Anhui Provincial Department of Education under Grant No. AQKJ2015B016, and the Key Project of Natural Science Research of Anhui Provincial Department of Education under Grant no. KJ2016A431.

\section{References}

[1] Martinović M, Damir Ž, Stipetić S, et. al., "Influence of winding design on thermal dynamics of permanent magnet traction motor," 22nd International Symposium on Power Electronics, Electrical Drives, Automation and Motion-SPEEDAM, 2014.

[2] Kefalas T D, Kladas A G, "Thermal Investigation of Permanent-Magnet Synchronous Motor for Aerospace Applications," IEEE Trans. Industrial Electronics, vol. 61, no. 8, pp. 4404-4411. 2014.

[3] Xuzhen H, Jiaxi L, Chengming Z, "Calculation and experimental study on temperature rise of a high overload tubular permanent magnet linear motor," IEEE Trans. Plasma Science, vol. 41, no. 5, pp. 1182-1187, 2013.

[4] Tae-Chul Jeong, Won-Ho Kim, Mi-Jung Kim, KiDeok Lee, Jae-Jun Lee, Jung-Ho Han, Tae-Hyun Sung, Hee-Jun Kim, Ju Lee, "Current Harmonics Loss Analysis of $150-\mathrm{kW}$ Traction Interior Permanent Magnet Synchronous Motor Through Co-Analysis of Axis Current Control and Finite Element Method," in Magnetics, IEEE Transactions on, vol. 49, no. 5, pp. 2343-2346, May 2013.

[5] Yamazaki, K., Seto, Y., "Iron loss analysis of interior permanent magnet synchronous motors-variation of main loss factors due to driving condition," IEEE Trans. Industry Applications, vol. 42, no. 4, pp. 10451052, July-Aug. 2006.

[6] Ping Chen, Renyuan Tang, Wenming Tong, Xueyan Han, Jianguo Jia, Xiaofeng Zhu, "Analysis of losses of permanent magnet synchronous motor with PWM supply," in Electrical Machines and Systems (ICEMS), 2014 17th International Conference on, vol., no., pp. 1119-1124, 22-25 Oct. 2014.

[7] DING Shuye, LIU Shuqi, BI Liuxin, et. al., "Loss Analysis for Permanent Magnet Synchronous Motor under Vector Control," Journal of Xi'an Jiao Tong University, Vol. 12, pp. 95-101, 2013.

[8] DING Shuye, GUO Baocheng, et.al., "Temperature Field Investigation of Permanent Magnet Synchronous Motors Controlled by the Frequency Conversion Control System," Proceedings of the CSEE, Vol. 34, no. 9, pp. 1368-1375, 2014.
[9] Shafigh Nategh, "Thermal Analysis and Management of High-Performance Electrical Machines," Kungliga Tekniska högskolan, Stockholm, Sweden, 2013.

[10] Luo Fuqiang, Xia Changliang, et.al., "Model of Equivalent Iron Loss Resistance of Induction Motor Fed by PWM," Trans of China Electrotechnical Society, vol. 27, no. 7, pp. 101-108. 2012.

[11] WANG Ai-yuan, HUANG Su-rong, GONG Jun, "Thermal Simulation of High - Density IPM Motor Operating Process Using Lump e d Parameter Thermal Model," Small \& Special Electrical Machines, vol. 32, no. 8, pp. 5-7, 2004.

[12] Kim, K. S, Lee, B. H, Hong J. P, "Improvement of Thermal Equivalent Circuit Network and Pre diction on Heat Characteristic of Motor by Calculatio n of Convection Heat Transfer Coefficient," Electrom agnetic Field Problems and Applications (ICEF), 20 12 Sixth International Conference on. IEEE, pp. 1-4, 2012

[13] El-Refaie A M, Alexander J P, Galioto S, et.al., "Advanced high power-density interior permanent magnet motor for traction applications," Energy Conversion Congress and Exposition (ECCE), 2013 IEEE. IEEE, pp. 581-590. 2013

[14] Wenying Jiang, "Coupled Electromagnetic Thermal Machine Design Optimization Based on Finite Element Analysis Using High-Throughput Computing," University of Wisconsin-Madison, 2014

[15] Zhang Qi, Wang Weixu, Huang Surong, Guo Jianwen. "Heat Tansfer Simulation of High Density Permanent Magnet Motor for Vehicles Based on Fluid-Solid Coupling Method," Electric Machines \& Control Application, vol. 8, pp. 86-90. 2012

[16] Tang Yunqiu, Liang Yanping, "Analysis and calculation of electromagnetic field of electric machine," China Machine Press, Cha. 4, 2010

[17] Harris T A, Kotzalas M N, Luo Jiwei, Ma Wei, et.al., "Rolling Bearing Analysis Essential Concepts of Bearing Technology," China Machine Press, Chap.4, 2009.

[18] Zhang Qi, Lu Xirui, Huang Surong, Zhang Jun, "Temperature Rise Calculations of High Density Permanent Magnet Motors Based on Multi-domain Co-simulation," Proceedings of the CSEE, vol. 34, no. 12, pp. 1874-1881, 2014.

[19] Zhang Hanni, "Analysis of Thermal Performance for High Power Density Permanent Magnet Motor with Consideration of Heat Transfer in Bearings," Shanghai University, Shanghai, 2015.

[20] A.N. Bao Li SAST, et.al., "Air dynamics and heat transfer in electric machine," China Machine Press, chap. 5, 1985.

[21] Li Shoufa, "Magnetic Field Analysis and Thermal Field Calculation of an Induction Motor with Broken-Bars Fault," Harbin University of Science and Technology, Harbin, 2007. 


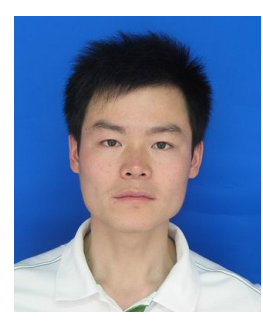

ShiJun Chen $\mathrm{He}$ received the B.S. degree in Automation in 2006 from East China University of Technology. He received the M.S. degree in Control Theory and Control Engineering in 2010 from Guangdong University of Technology. He is currently a lecturer of Anqing Normal University and now studying for a $\mathrm{PhD}$ at Shanghai University.

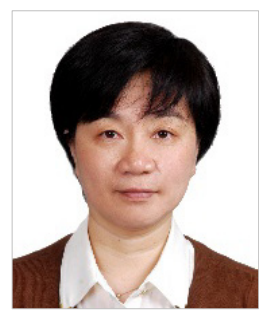

Qi Zhang She received B. Eng. from and joined in Elec. Eng. Dept., Shanghai University of Technology, Shanghai, China, in 1984, received M. Eng. and Ph.D. from Elec. Eng. Dept., Shanghai University, Shanghai, China, in 1991 and 2009, respectively. She is now a Prof. in Automation Dept., Shanghai University, Shanghai, China, interested in fundamental theory, design methods, and simulation techniques for high quality permanent magnet motor and the motor of new structures.

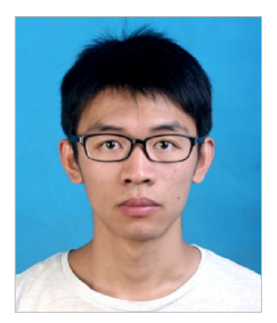

Biao He He received the B.S. degree in Electrical Engineering and Automation in 2014 from Xi'an University of Technology. He is currently studying for a M.S. degree at Shanghai University. His research interest is losses analysis in PMSM.

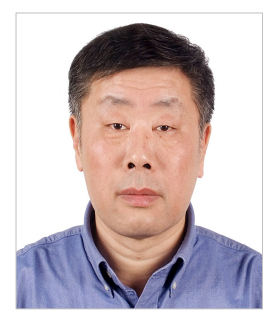

SuRong Huang $\mathrm{He}$ received his Diploma degree from the Shanghai Institute of Mechanics, Shanghai, China, in 1977. He is currently a Professor and Doctoral Supervisor in the Department of Automation, Shanghai University, Shanghai, China. His current research interests include the design, control, modeling and simulation of electrical machines and ac drives, and the vibration and noise of electrical machines.

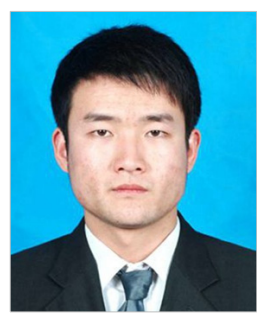

Dou-Dou Hui He received the B.S. degree in Electrical Engineering and Automation in 2014 from Anhui University. He is currently studying for a M.S. degree at Shanghai University. His research interest is the vibration and noise of PMSM. 